\title{
Genotyping of turkey coronavirus field isolates from various geographic locations in the Unites States based on the spike gene
}

\author{
Yi-Ning Chen ${ }^{1,2}$ Chien Chang Loa ${ }^{1,3}$ Mustafa Mohammed-Khair Ababneh ${ }^{1,4}$. \\ Ching Ching $\mathrm{Wu}^{1,5} \cdot$ Tsang Long $\operatorname{Lin}^{1}$
}

Received: 2 April 2015/Accepted: 27 July 2015/Published online: 8 August 2015

(C) Springer-Verlag Wien 2015

\begin{abstract}
Turkey flocks have experienced turkey coronaviral enteritis sporadically in the United States since the 1990s. Twenty-four field isolates of turkey coronavirus (TCoV) from multiple states in the United States were recovered from 1994 to 2010 to determine the genetic relationships among them. The entire spike (S) gene of each TCoV isolate was amplified and sequenced. Pairwise comparisons were performed using the Clustal W program, revealing $90.0 \%$ to $98.4 \%$ sequence identity in the fulllength S protein, $77.6 \%$ to $96.6 \%$ in the amino terminus of the S1 subunit (containing one hypervariable region in $\mathrm{S} 1 \mathrm{a})$, and $92.1 \%$ to $99.3 \%$ in the S2 subunit at the deduced amino acid sequence level. The conserved motifs, including two cleavage recognition sequences of the $\mathrm{S}$ protein, two heptad repeats, the transmembrane domain,
\end{abstract}

Electronic supplementary material The online version of this article (doi:10.1007/s00705-015-2556-2) contains supplementary material, which is available to authorized users.

Tsang Long Lin

tllin@purdue.edu

1 Department of Comparative Pathobiology, Purdue University, 406 South University Street, West Lafayette, IN 47907, USA

2 Department of Bioscience Technology, Chung Yuan Christian University, 200 Chung Pei Road, Chung Li 32023, Taiwan, ROC

3 Present Address: Mylan Pharmaceuticals Inc., 3711 Collins Ferry Road, Morgantown, WV 26505, USA

4 Present Address: Department of Basic Veterinary Medical Sciences, Jordan University of Science and Technology, Irbid 22110, Jordan

5 Present Address: School of Veterinary Medicine, National Taiwan University, No. 1, Sec. 4, Roosevelt Road, Taipei 10617, Taiwan, ROC and the Golgi retention signal were identified in all $\mathrm{TCoV}$ isolates. Phylogenetic analysis based on the full-length $\mathrm{S}$ gene was used to distinguish North American TCoV isolates from French TCoV isolates. Among the North American TCoV isolates, three distinct genetic groups with $100 \%$ bootstrap support were observed. North Carolina isolates formed group I, Texas isolates formed group II, and Minnesota isolates formed Group III. The S genes of $24 \mathrm{TCoV}$ isolates from the United States remained conserved because they contained predominantly synonymous substitutions. The findings of the present study suggest endemic circulation of distinct TCoV genotypes in different geographic locations.

\section{Introduction}

Turkey coronaviral enteritis of varying severity, caused by turkey coronavirus (TCoV), has been reported in turkey flocks from multiple states in the United States since the 1990s. The major clinical signs of TCoV infection include depression, ruffled feathers, diarrhea, decreased body weight, and uneven flock growth. The most apparent gross lesions are markedly distended intestines with gaseous and watery content, particularly in the ileum and ceca. Salient histopathologic findings include shortening of the intestinal villi, an increase in crypt depth, and widening of intervillous spaces [1]. When turkeys are infected with $\mathrm{TCoV}$ and other infectious agents such as astrovirus, small round virus, and Escherichia coli (E. coli), they can develop poult enteritis-mortality syndrome (PEMS), which causes high mortality [2,3]. Subsequent experimental studies of the TCoV isolates VR-911 and TCoV/ON/MG10/08 from Canada have shown that $\mathrm{TCoV}$ can cause symptoms 
similar to those caused by PEMS [3, 4]. Therefore, TCoV has been suggested to be the major causative pathogen for turkey enteritis, and secondary infections caused by other opportunistic microorganisms enhance the severity of TCoV enteritis and contribute to the development of PEMS. Turkey enteritis associated with TCoV infection has caused substantial economic losses in Indiana, North Carolina, Arkansas, and other states in the United States [5, 6], as well as in Canada [4], Europe [2, 7], and Brazil [8]. Currently, there are no vaccines to prevent the disease, and treatment of infected turkeys is often unsuccessful.

A member of the species Avian coronavirus ( $\mathrm{CoV})$ in the genus Gammacoronavirus and family Coronaviridae, TCoV has a positive single-stranded RNA genome that is approximately $27 \mathrm{~Kb}$ in size. The major structural proteins of $\mathrm{TCoV}$ include the spike (S), envelope (E), matrix (M), and nucleocapsid (N) proteins. Comparisons of 3'-end coding regions [9, 10] as well as the full genomes [11] of TCoV isolates and infectious bronchitis virus (IBV) have suggested that TCoV arises through recombination in the $S$ gene, because pairwise comparisons of S gene sequences have revealed only a $34 \%$ similarity between $\mathrm{TCoV}$ isolates and IBV strains, whereas gene $3, \mathrm{M}$ gene, gene 5 , and $\mathrm{N}$ gene sequences have over $80 \%$ similarity $[9,11,12]$. The $\mathrm{S}$ gene sequences of different $\mathrm{TCoV}$ isolates (93\%-99.7\%) are more conserved than those of various IBV strains (67.4\%-94.4\%), which could explain the close antigenic relationship of TCoV isolates compared with the distant antigenicity of different IBV serotypes [5, 10, 13, 14]. Investigations during $\mathrm{TCoV}$ outbreaks and genomic analyses of TCoV isolates have revealed that distinct $\mathrm{TCoV}$ isolates tend to circulate endemically, and their respective sequences group phylogenetically according to their state of origin $[6,7,11]$. However, these observations may have been biased because of the small number of TCoV sequences that were analyzed. In the present study, $24 \mathrm{TCoV}$ isolates were recovered from clinical cases submitted to the Indiana Animal Disease Diagnostic Laboratory at Purdue University by turkey farms in Minnesota, Indiana, North Carolina, Missouri, Arkansas, Texas, South Carolina, and Pennsylvania between 1994 and 2010. The objective of the present study was to elucidate the relationship between the genotypes and geographic distribution of $\mathrm{TCoV}$ isolates from turkey farms in multiple states in the United States by using sequence analysis and comparing the full-length $\mathrm{S}$ gene.

\section{Materials and methods}

\section{Clinical samples and virus purification}

Twenty-four field isolates of $\mathrm{TCoV}$ were recovered from clinical cases submitted to the Animal Disease Diagnostic Laboratory at Purdue University by turkey farms in
Minnesota, Indiana, North Carolina, Missouri, Arkansas, Texas, South Carolina, and Pennsylvania between 1994 and 2010 (Table 1). Field cases of TCoV were confirmed by clinical signs, gross lesions, histopathologic findings, immunofluorescence antibody (IFA) assay with antiserum against TCoV/IN/540/94, electron microscopy, and reverse transcription polymerase chain reaction (RT-PCR). All 24 $\mathrm{TCOV}$ isolates were propagated five times in embryonated turkey eggs as described previously [1]. In brief, intestines from $\mathrm{TCoV}$-infected turkeys were homogenized as $20 \%$ suspensions in chilled sterile phosphate-buffered saline and clarified by centrifugation at $3000 \mathrm{rpm}$ for 10 minutes at $4{ }^{\circ} \mathrm{C}$. The supernatant was filtered through a $0.22-\mu \mathrm{m}$ membrane filter (Millipore, Bedford, MA, USA). The filtrate was inoculated into the amniotic cavity of 22-day-old embryonated turkey eggs. The embryo intestines were harvested after 3 days of incubation for virus purification. The harvested intestines were homogenized and clarified at $3000 \mathrm{rpm}$ for 10 minutes at $4{ }^{\circ} \mathrm{C}$. The supernatant was layered on top of $30 \%$ and $60 \%$ sucrose and clarified using ultracentrifugation in an SW28 rotor at $24,000 \mathrm{rpm}$ for 3 hours at $4{ }^{\circ} \mathrm{C}$ in an Optima XL-100K ultracentrifuge (Beckman Coulter, Fullerton, CA, USA). The interface between $30 \%$ and $60 \%$ sucrose was collected and placed on top of a continuous $40 \%-60 \%$ sucrose gradient and clarified by ultracentrifugation at $24,000 \mathrm{rpm}$ for 20 hours at $4{ }^{\circ} \mathrm{C}$. A band of buoyant density $1.16-1.24 \mathrm{~g} / \mathrm{mL}$ (containing $\mathrm{TCoV}$ ) was collected and saved at $-80{ }^{\circ} \mathrm{C}$ as the viral stock.

\section{RNA and CDNA}

The viral RNA was extracted from the purified virus using RNApure $^{\text {TM }}$ Reagent (GenHunter, Nashville, TN, USA) and chloroform, followed by precipitation using cold isopropyl alcohol and ethanol. The extracted RNA was reverse transcribed to cDNA using SuperScript ${ }^{\mathrm{TM}}$ III reverse transcriptase (Invitrogen, Carlsbad, CA, USA) according to the manufacturer's instructions. The first reaction was 10 minutes of incubation with the RNA, random hexamer primer $(100 \mathrm{ng} / \mu \mathrm{L})$, and $10 \mathrm{mM} d N T P s$ at $70{ }^{\circ} \mathrm{C}$, followed by 1 minute on ice. The second reaction was 5 minutes of incubation with a mixture of $5 \mathrm{x}$ firststrand buffer, $0.1 \mathrm{M}$ of dithiothreitol (DTT), $1 \mathrm{U}$ of SuperScript $^{\mathrm{TM}}$ III reverse transcriptase, and $40 \mathrm{U}$ of RNaseOUT $^{\mathrm{TM}}$ (Invitrogen, Carlsbad, CA, USA) at $25^{\circ} \mathrm{C}$, followed by 1 hour of incubation at $50{ }^{\circ} \mathrm{C}$ and 15 minutes of inactivation at $70{ }^{\circ} \mathrm{C}$.

\section{PCR amplification and sequencing}

The full-length S gene (approximately $3.9 \mathrm{~kb}$ ) was amplified by PCR using the cDNA of each TCoV isolate with the 
Table 1 Turkey coronavirus $(\mathrm{TCoV})$ isolates and other coronaviruses used in the molecular analysis of the spike (S) gene

\begin{tabular}{|c|c|c|c|c|}
\hline Isolate $^{\mathrm{a}}$ & Year & Location & Accession number & Reference \\
\hline TCoV/MN/ATCC/76 & 1976 & Minnesota, USA & EU022526 & [15] \\
\hline TCoV/MN/310/96 & 1996 & Minnesota, USA & KF652237 & This study \\
\hline TCoV/IN/517/94 & 1994 & Indiana, USA & GQ427175 & [11] \\
\hline TCoV/IN/517-Purdue/94 & 1994 & Indiana, USA & KF652222 & This study \\
\hline TCoV/IN/540/94 & 1994 & Indiana, USA & EU022525 & [15] \\
\hline TCoV/IN/671/04 & 2004 & Indiana, USA & KF652220 & This study \\
\hline TCoV/IN/834/04 & 2004 & Indiana, USA & KF652221 & This study \\
\hline TCoV/IN/287/09 & 2009 & Indiana, USA & KF652219 & This study \\
\hline TCoV/IN/421/10 & 2010 & Indiana, USA & KF652218 & This study \\
\hline $\mathrm{TCoV} / \mathrm{NC} / 1020 / 96$ & 1996 & North Carolina, USA & KF652227 & This study \\
\hline TCoV/NC/DK9/97 & 1997 & North Carolina, USA & KF652240 & This study \\
\hline TCoV/NC/1440/99 & 1999 & North Carolina, USA & KF652238 & This study \\
\hline TCoV/NC/183-1/02 & 2002 & North Carolina, USA & KF652230 & This study \\
\hline $\mathrm{TCoV} / \mathrm{NC} / 625 / 02$ & 2002 & North Carolina, USA & KF652224 & This study \\
\hline $\mathrm{TCoV} / \mathrm{NC} / 20 / 09$ & 2009 & North Carolina, USA & KF652223 & This study \\
\hline $\mathrm{TCoV} / \mathrm{NC} / 1741 / 12$ & 2012 & North Carolina, USA & KJ146015 & {$[6]$} \\
\hline $\mathrm{TCoV} / \mathrm{NC} / 1729 / 12$ & 2012 & North Carolina, USA & KJ146017 & {$[6]$} \\
\hline $\mathrm{TCoV} / \mathrm{NC} / 1728 / 12$ & 2012 & North Carolina, USA & KJ146018 & [6] \\
\hline TCoV/MO/168/99 & 1999 & Missouri, USA & KF652229 & This study \\
\hline TCoV/MO/2216/99 & 1999 & Missouri, USA & KF652231 & This study \\
\hline TCoV/MO/2580/99 & 1999 & Missouri, USA & KF652232 & This study \\
\hline TCoV/MO/333/06 & 2006 & Missouri, USA & KF652239 & This study \\
\hline TCoV/AR/428/96 & 1996 & Arkansas, USA & KF652234 & This study \\
\hline TCoV/AR/1425/96 & 1996 & Arkansas, USA & KF652228 & This study \\
\hline TCoV/AR/1811/12 & 2012 & Arkansas, USA & KJ146016 & {$[6]$} \\
\hline TCoV/AR/1913/12 & 2012 & Arkansas, USA & KJ146019 & {$[6]$} \\
\hline TCoV/AR/1744/12 & 2012 & Arkansas, USA & KJ146020 & {$[6]$} \\
\hline TCoV/TX/1038-Purdue/98 & 1998 & Texas, USA & KF652225 & This study \\
\hline TCoV/TX/1038/98 & 1998 & Texas, USA & GQ427176 & [11] \\
\hline TCoV/TX/GL/01 & 2001 & Texas, USA & GQ427174 & [11] \\
\hline $\mathrm{TCoV} / \mathrm{TX} / 176-2 / 02$ & 2002 & Texas, USA & KF652226 & This study \\
\hline TCoV/SC/284/96 & 1996 & South Carolina, USA & KF652233 & This study \\
\hline TCoV/PA/682/98 & 1998 & Pennsylvania, USA & KF652236 & This study \\
\hline TCoV/PA/640/02 & 2002 & Pennsylvania, USA & KF652235 & This study \\
\hline TCoV/VA/74/03 & 2003 & Virginia, USA & GQ427173 & [11] \\
\hline TCoV/ON/MG10/08 & 2008 & Ontario, Canada & EU095850 & {$[4]$} \\
\hline TCoV/FR070341j/07 & 2007 & France & GQ411201 & {$[7]$} \\
\hline TCoV/FR080147c/08 & 2008 & France & FN434203 & [7] \\
\hline TCoV/FR080183j/08 & 2008 & France & FN545819 & [7] \\
\hline TCoV-0/BR/08 & 2008 & Brazil & HQ853282 & Direct submission \\
\hline IBV/Beaudette CK & 1937 & United Kingdom & AJ311317 & [23] \\
\hline IBV/Arkansas DPI & 1981 & Arkansas, USA & GQ504720 & [24] \\
\hline Guinea fowl CoV/FR/2011 & 2011 & France & HF544506 & {$[25]$} \\
\hline Beluga whale SW1 CoV & 2008 & Missouri, USA & EU111742 & {$[26]$} \\
\hline
\end{tabular}

primers Sup and Sdown3 (Online Resource 1). The mixture (64:1, v:v) of Taq (Promega Corp., Madison, WI, USA) and Pfu DNA polymerases (Stratagene, La Jolla, CA, USA) with proofreading ability was used in a 96-well thermal cycler (GeneAmp, Perkin-Elmer Cetus Corp., Norwalk, CT, USA) to maintain the fidelity of the PCR [9]. The PCR products were electrophoresed on $1 \%$ agarose gels and purified using a Zymoclean ${ }^{\mathrm{TM}}$ Gel DNA Recovery Kit 
(Zymo, Irvine, CA, USA) for further sequencing. Several primers (Online Resource 1) designed to sequence overlapping fragments covering the full length of the $S$ gene of TCoV were used to determine the nucleotide sequences of the purified PCR products at the Purdue University Genomics Core Facility (West Lafayette, IN, USA). In addition, the purified PCR product was cloned into the PCR-II plasmid vector and used to transform E. coli strain TOP10F' according to the manufacturer's instructions (Invitrogen, Carlsbad, CA, USA).

\section{Sequence analysis}

Twenty-four TCoV isolates collected from eight states in the United States from 1994 to 2010 were purified and sequenced in our laboratory. TCoV/IN/549/94 was analyzed in a previous study [15], and the full-length $S$ gene sequences of the other $23 \mathrm{TCoV}$ isolates were published for the first time in the present study (Table 1). The putative peptide cleavage site separating the amino-terminus of the $\mathrm{S} 1$ subunit from the carboxyl terminus of the $\mathrm{S} 2$ subunits as well as a second possible peptide cleavage site in the S2 subunit were detected using the ProP server (http://www. cbs.dtu.uk/services/ProP/). The S1 subunit of TCoV was further designated as S1a at the amino-terminus (1-204 in TCoV/IN/540/94) and S1b at the carboxyl-terminus (205536 in TCoV/IN/540/94) [7]. Figure 1 shows a diagram of the $\mathrm{S}$ protein of TCoV. The nucleotide and deduced amino acid sequence similarities of the $\mathrm{S}$ genes of all $24 \mathrm{TCoV}$ isolates were analyzed using the Clustal W alignment method in MEGA6 [16]. A phylogenetic tree based on fulllength nucleotide sequences of the $S$ gene was constructed using the maximum-likelihood method and the Kimura 2-parameter model. A phylogenetic tree based on deduced amino acid sequences of the S1a subunit, containing a hypervariable region (HVR), was constructed using the neighbor-joining method and the Jones-Taylor-Thornton model. A codon-based Z-test of positive selection for $\mathrm{S}$ gene sequences of various $\mathrm{TCoV}$ isolates was conducted to analyze the differences in the number of nonsynonymous $(\mathrm{dN})$ and synonymous (dS) substitutions per site by using the Nei-Gojobori method [17] in MEGA6. The variance of both trees and codon-based Z-test were validated using 1000 bootstrap replicates.

\section{Nucleotide sequence accession numbers}

The $\mathrm{S}$ sequences of TCoV isolates reported in the present study were submitted to the GenBank databse, and their accession numbers ranged from KF652218 to KF652240. The accession numbers of other CoVs used for phylogenetic analysis are also listed in Table 1.

\section{Results}

\section{Genetic analysis of the spike sequences of turkey coronavirus isolates}

The sizes of the $\mathrm{S}$ genes of TCoV isolates reported in the present study ranged from 3609 to 3630 nucleotides. All 24 TCoV isolates exhibited similar $\mathrm{S}$ protein sequences (Fig. 1). The consensus transcription-regulating sequence (TRS), CTGAACAA, was identified 52 nucleotides upstream of the start codon of the $\mathrm{S}$ protein. Several conserved motifs and one HVR were found in all TCoV isolates, and their sequences are listed for comparison in Table 2. The consensus motif RXRR/X ( $\mathrm{X}$ is any amino
Fig. 1 Schematic diagram of the spike protein of turkey coronavirus. TRS, transcription regulatory sequence; SP, signal peptide; HVR, hypervariable region; HR, heptad repeat; TM, transmembrane domain; $\mathrm{CP}$, cytoplasmic peptides. Numbers in parentheses indicate the amino acid position from the start codon of the spike protein from TCoV/IN/540/94 (EU022525)

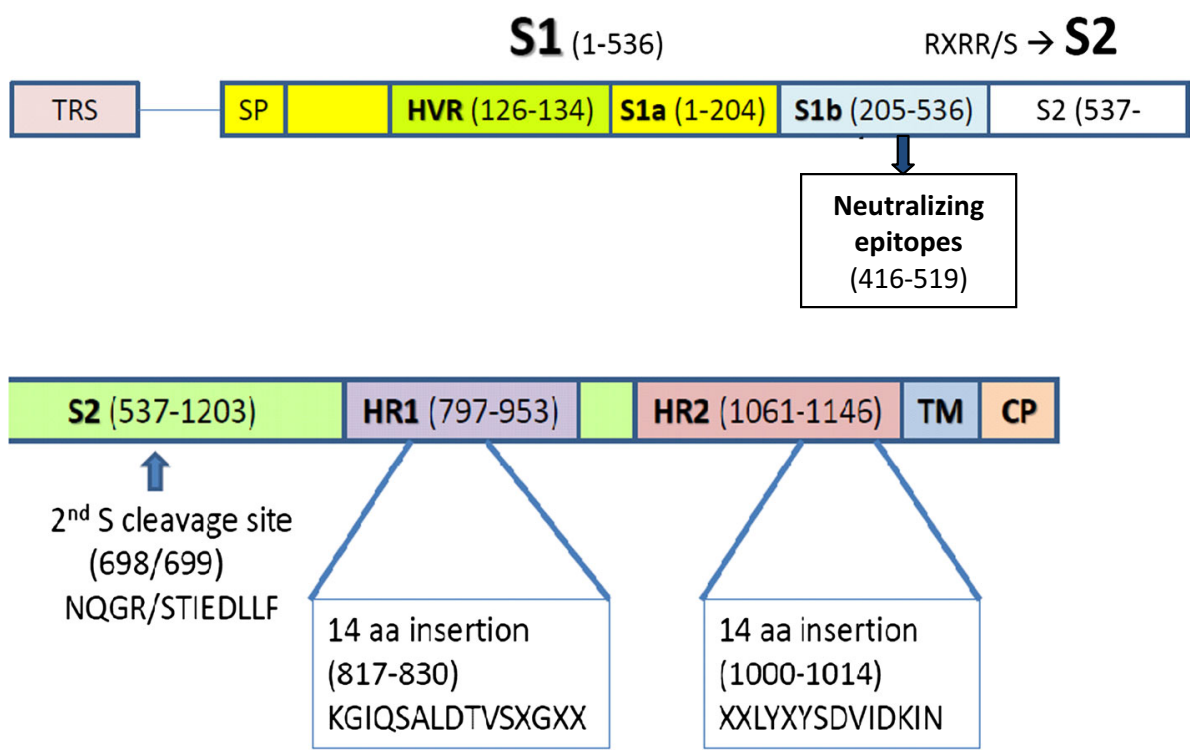


Table 2 Conserved motifs in the spike (S) protein cleavage sites and the sequences of the hypervariable region (HVR) of turkey coronavirus $(\mathrm{TCoV})$ isolates

\begin{tabular}{|c|c|c|c|c|}
\hline Isolate & $S$ full length (aa) & Hypervariable region (HVR) (126-134)* & S1/S2 cleavage $(536)^{*}$ & S2 2nd site $(698)^{*}$ \\
\hline TCoV/ATCC/MN/76 & 1203 & LSMGN_-ST & RRRR ATS & NQGR/S \\
\hline $\mathrm{TCoV} / 310 / \mathrm{MN} / 96$ & 1203 & LSMGN_-ST & RRRR ATS & NQGR/S \\
\hline TCoV/IN/517/94 & 1226 & LATNVGKVTPP-ND & $\mathrm{RKRR} / \mathrm{S}$ & NQGR/S \\
\hline TCoV/IN/517-Purdue/94 & 1205 & LGT-KVGD-HD & $\mathrm{RERR} / \mathrm{S}$ & NQGR/S \\
\hline TCoV/IN/540/94 & 1203 & LGT-KVGD-HD & RERR/S & NQGR/S \\
\hline TCoV/IN/671/04 & 1209 & IDTNVGKVTPP-HE & $\mathrm{RKRR} / \mathrm{S}$ & NQGR/S \\
\hline TCoV/IN/834/04 & 1209 & VYTNVGKVTPP-NE & $\mathrm{RKRR} / \mathrm{S}$ & NQGR/S \\
\hline TCoV/IN/287/09 & 1209 & LITNVGD—HD & $\mathrm{RKRR} / \mathrm{S}$ & NQGR/S \\
\hline TCoV/IN/421/10 & 1208 & IETNVGK-TPP-ND & RRRR/S & NQGR/S \\
\hline $\mathrm{TCoV} / \mathrm{NC} / 1020 / 96$ & 1208 & LVTNAGNVKP-DD & $\mathrm{RKRR} / \mathrm{S}$ & NQGR/S \\
\hline TCoV/NC/DK9/97 & 1209 & LHTNVGKVTPP-ND & RKRR/S & NQGR/S \\
\hline $\mathrm{TCoV} / \mathrm{NC} / 1440 / 99$ & 1207 & VSTNAGKVR—ND & RERR/S & NQGR/S \\
\hline $\mathrm{TCoV} / \mathrm{NC} / 183-1 / 02$ & 1208 & IGTNVGKKPP-NE & RKRR/S & NQGR/S \\
\hline $\mathrm{TCoV} / \mathrm{NC} / 625 / 02$ & 1208 & VATNVGKSAPWAND & RRRR/S & NQGR/S \\
\hline $\mathrm{TCoV} / \mathrm{NC} / 20 / 09$ & 1209 & INTNAGKITLP-NE & $\mathrm{RKRR} / \mathrm{S}$ & NQGR/S \\
\hline $\mathrm{TCoV} / \mathrm{NC} / 1728 / 12$ & $\mathrm{NA}^{\mathrm{b}}$ & MDTNVGK-PN-ND & RRRR/S & $\mathrm{NA}^{\mathrm{b}}$ \\
\hline $\mathrm{TCoV} / \mathrm{NC} / 1729 / 12$ & $\mathrm{NA}^{\mathrm{b}}$ & IDTNVGK-PN-ND & RRRR/S & $\mathrm{NA}^{\mathrm{b}}$ \\
\hline $\mathrm{TCoV} / \mathrm{NC} / 1741 / 12$ & $\mathrm{NA}^{\mathrm{b}}$ & IDTNVGK-PN-NH & RRRR/S & $\mathrm{NA}^{\mathrm{b}}$ \\
\hline TCoV/MO/168/99 & 1207 & VGTNAGKQ-KE & RKRR/S & NQGR/S \\
\hline $\mathrm{TCoV} / \mathrm{MO} / 2216 / 99$ & 1206 & VSTNAGQKP-NE & RKRR/S & NQGG/S \\
\hline $\mathrm{TCoV} / \mathrm{MO} / 2580 / 99$ & 1206 & IGTNAGKV—ND & RKRR/S & NQGR/S \\
\hline TCoV/MO/333/06 & 1206 & IDTNAGKVGP-KD & RKRR/S & NQGR/S \\
\hline TCoV/AK/428/96 & 1203 & LKVAN-SH- & RKRR/S & NQGR/S \\
\hline TCoV/AK/1425/96 & 1204 & IETNVGK-SH—NE & RKRR/S & NQGR/S \\
\hline TCoV/AK/1744/12 & $N A^{b}$ & VGTNAGKVSAPNE & RKRR/S & $\mathrm{NA}^{\mathrm{b}}$ \\
\hline TCoV/AK/1913/12 & $\mathrm{NA}^{\mathrm{b}}$ & IDTNVGK-S-YD & $\mathrm{RKRR} / \mathrm{S}$ & $\mathrm{NA}^{\mathrm{b}}$ \\
\hline TCoV/TX/1038-Purdue/98 & 1202 & INTKG $-\mathrm{ND}$ & $\mathrm{RMRR} / \mathrm{S}$ & NQGR/S \\
\hline TCoV/TX/1038/98 & 1223 & IGTNADKKS—ND & RTRR/S & NQGR/S \\
\hline TCoV/TX/GL/01 & 1225 & IEINAGEVT—ND & RTRR/S & NQGR/S \\
\hline $\mathrm{TCoV} / \mathrm{TX} / 176-2 / 02$ & 1207 & IGTNADKKS—ND & $\mathrm{RMRR} / \mathrm{S}$ & NQGR/S \\
\hline $\mathrm{TCoV} / \mathrm{SC} / 284 / 96$ & 1207 & LVTNVGNVKT-AD & RKRR/S & NQGR/S \\
\hline TCoV/PA/682/98 & 1203 & $\mathrm{LSMGN} \longrightarrow \mathrm{ST}$ & RRRW ATS & NQGR/S \\
\hline TCoV/PA/640/02 & 1208 & IYTNVGKLTP-ND & $\mathrm{RKRR} / \mathrm{S}$ & NQGR/S \\
\hline TCoV/VA/74/03 & 1226 & LATNVGKVTPPND & RKRR/S & NQGR/S \\
\hline TCoV/ON/MG10/08 & 1226 & LATNVGKVTPPND & RKRR/S & NQGR/S \\
\hline TCoV-0 10/BR/08 & & LATNVGKVTPPND & RKRR/S & NQGR/S \\
\hline TCoV/FR070341j/07 & 1198 & SIGNFVLNS & RSRR/S & PQGR/S \\
\hline TCoV/FR080147c/08 & 1198 & SIGNFVLNS & RSRR/S & PQGR/S \\
\hline TCoV/FR080183j/08 & 1198 & SIGNFVLNS & RSRR/S & PQGR/S \\
\hline
\end{tabular}

a The positions of HVR, S1/S2 cleavage, and S2 second predicted cleavage site in parentheses were relative to the start codon of the spike protein of TCoV/IN/540/94 (EU022525)

b NA: data not available

acid, $\mathrm{R}$ is arginine, and slash [/] indicates the cleavage position) was found at the cleavage site for the $\mathrm{S} 1$ and $\mathrm{S} 2$ subunits in $22 \mathrm{TCoV}$ isolates analyzed in the present study and the French TCoV isolates, except for the isolates TCoV/MN/310/96 and TCoV/PA/682/98, which had the amino acid sequence ATS followed by the cleavage site, similar to TCoV/MN/ATCC/76. A conserved sequence, NQGR/S, resembling the furin-dependent cleavage site in IBV [18] was identified in the S2 subunit in all $\mathrm{TCoV}$ isolates except the isolate $\mathrm{TCoV} / \mathrm{MO} / 2216 / 99$, in which the 
critical arginine was mutated to glycine and the second probable protein cleavage site was lost. Rather than NQGR/S, French TCoV isolates had the PQGR/S sequence as the conserved cleavage motif in the S2 subunit. Only one HVR, spanning amino acid positions 126 to 134 (TCoV/IN/540/94) was found in the TCoV isolates, rather than the three HVRs identified in IBV [7]. Two 14-aminoacid insertions in heptad repeats (HR1 and HR2), the consensus motif (YIKWPWYVWL) in the transmembrane domain, and the late Golgi retention signal (YYTTF) for S protein were also observed in all $24 \mathrm{TCoV}$ isolates. Among the 45 amino acid residues of the neutralizing-epitopecontaining $\mathrm{S}$ fragment in the $\mathrm{S} 1$ subunit identified in a previous study [19], 33 consensus residues were observed among the $24 \mathrm{TCoV}$ isolates (Online Resource 2).

\section{Comparison of the spike sequences of turkey coronavirus isolates}

A pairwise comparison of the deduced amino acid sequences of the $24 \mathrm{TCoV}$ isolates showed that the sequence identity ranged from $90.0 \%$ to $98.4 \%$ for the full-length S protein, $77.6 \%$ to $96.6 \%$ for the S1a subunit containing HVR, and $92.1 \%$ to $99.3 \%$ for the S2 subunit (Online Resource 3). No positive selection for the $\mathrm{S}$ gene was observed among the TCoV isolates (Online Resource 4). The values of $d_{S}$ were greater than those of $d_{N}$ in all comparisons except three pairs of $\mathrm{TCoV}$ isolates $(\mathrm{TCoV} /$ IN/540/94 and IN/517-Purdue/94, IN/671/04 and IN/834/ 04, MO/2216/99 and MO/168/99), which had similar $d_{S}$ and $d_{N}$ values and shared high sequence identity in the $S$ gene, exceeding $95 \%$.

\section{Phylogenetic analysis of the spike gene}

Phylogenetic trees based on the full-length $\mathrm{S}$ nucleotide sequences (Fig. 2A) and S1a amino acid sequences containing HVRs (Fig. 2B) of different CoVs of the genus Gammacoronavirus were generated. As shown in Figures $2 \mathrm{~A}$ and $2 \mathrm{~B}$, the IBV strains were separated from $\mathrm{TCoV}$ isolates, and North American TCoV isolates were separated from French $\mathrm{TCoV}$ isolates. Three genetic groups, referred to as groups I, II, and III, were observed in North American TCoV isolates (Fig. 2A). Group I included all North Carolina isolates except TCoV/NC/1020/96, Indiana isolates from 2004 and 2010, Missouri isolates from 1999, and isolates from Pennsylvania, Virginia, and Canada. Group II contained all Texas isolates, Indiana isolates from 1994 and 2009, one Missouri isolate each from 1999 and 2006, and North Carolina, South Carolina, and Arkansas isolates from 1996. Group III was composed of two Minnesota isolates that were isolated 20 years apart and TCoV/PA/682/98, and they had sequence identities higher than $98.5 \%$. Because of the high degree of variation, most phylogenetic groupings based on the S1a deduced amino acid sequences did not have a bootstrap value over $50 \%$ (Fig. 2B). Nevertheless, the Texas TCoV isolates of group II and all three $\mathrm{TCoV}$ isolates of group III shown in the phylogenetic tree based on the full-length $\mathrm{S}$ nucleotide sequences still clustered according to their S1a amino acid sequences containing their HVR.

\section{Discussion}

Turkey coronavirus isolates from different geographic areas in the United States have been shown to be antigenically related to one another [5]. In the present study, an antiserum against the isolate $\mathrm{TCoV} / \mathrm{IN} / 540 / 94$ reacted with all $24 \mathrm{TCoV}$ isolates from $\mathrm{TCoV}$-infected turkeys and embryos by IFA assay (data not shown). The close antigenicity among TCoV isolates was associated with the high similarity of the $\mathrm{S}$ gene sequences, which ranged from $90.4 \%$ to $99.4 \%$. The $\mathrm{S}$ genes of $\mathrm{TCoV}$ isolates were conserved compared with the diverse $\mathrm{S}$ genes among various IBV strains, which range from $67.4 \%$ to $94 \%$, resulting in the existence of many serotypes of IBV [10]. The emergence of new IBV serotypes has been postulated to involve the recombination of $\mathrm{S}$ genes of vaccine strains of IBV in the field $[20,21]$. In a previous study, different serotypes of TCoV/VA/73/03, TX/1038/98, and IN/517/94 were identified by using a neutralization test in conjunction with real-time RT-PCR despite the high level of amino acid sequence identity (96\% to $98 \%$ ) among these $\mathrm{TCoV}$ isolates [11]. Additional studies are necessary to clarify the antigenic relationships among the various $\mathrm{TCoV}$ isolates and serotypes.

In the present study, similar to previous findings with IBV strains, most of the variations in the $\mathrm{S}$ protein sequences among $\mathrm{TCoV}$ isolates were observed in the amino-terminal half. Along the alignment of these $\mathrm{S}$ protein sequences, the region of sequence with the most variation was between residues 126 and 134 of TCoV/IN/ $540 / 94$ from the start codon of the $\mathrm{S}$ protein. Various deletions occurred in this region in different $\mathrm{TCoV}$ isolates. This region is in the vicinity of HVR II (residues 117 to 131) of the IBV S protein. HVR I (residues 56 to 69), II, and III (residues 250 to 365) of the IBV S protein are associated with three neutralizing epitopes. The sequences of these regions could be used for differential diagnosis of IBV serotypes [13, 22]. By contrast, similar regions of high variation corresponding to HVR I or III of IBV were not detected among the TCoV isolates examined. These differences illustrate why the S proteins of IBV strains are more diverse than those of TCoV isolates. Similar phylogenetic trees were constructed using the full-length $\mathrm{S}$ and 
(A) Spike Gene Sequences

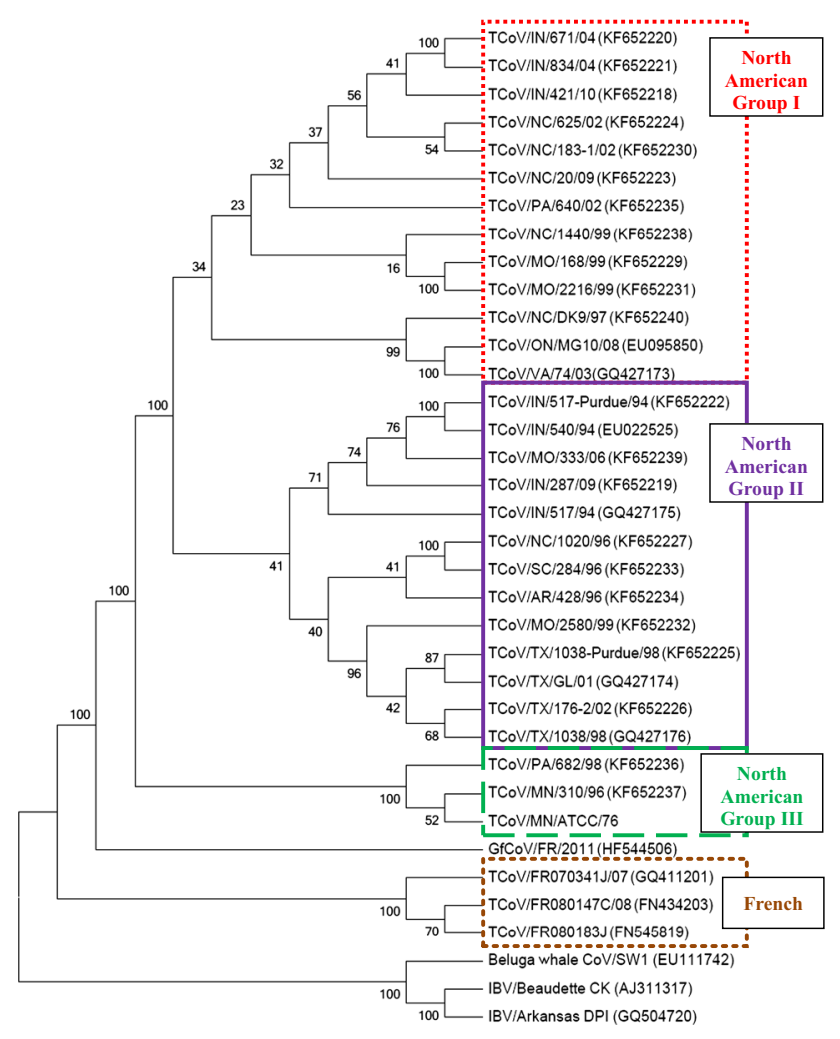

(B) Sla Amino Acid Sequences

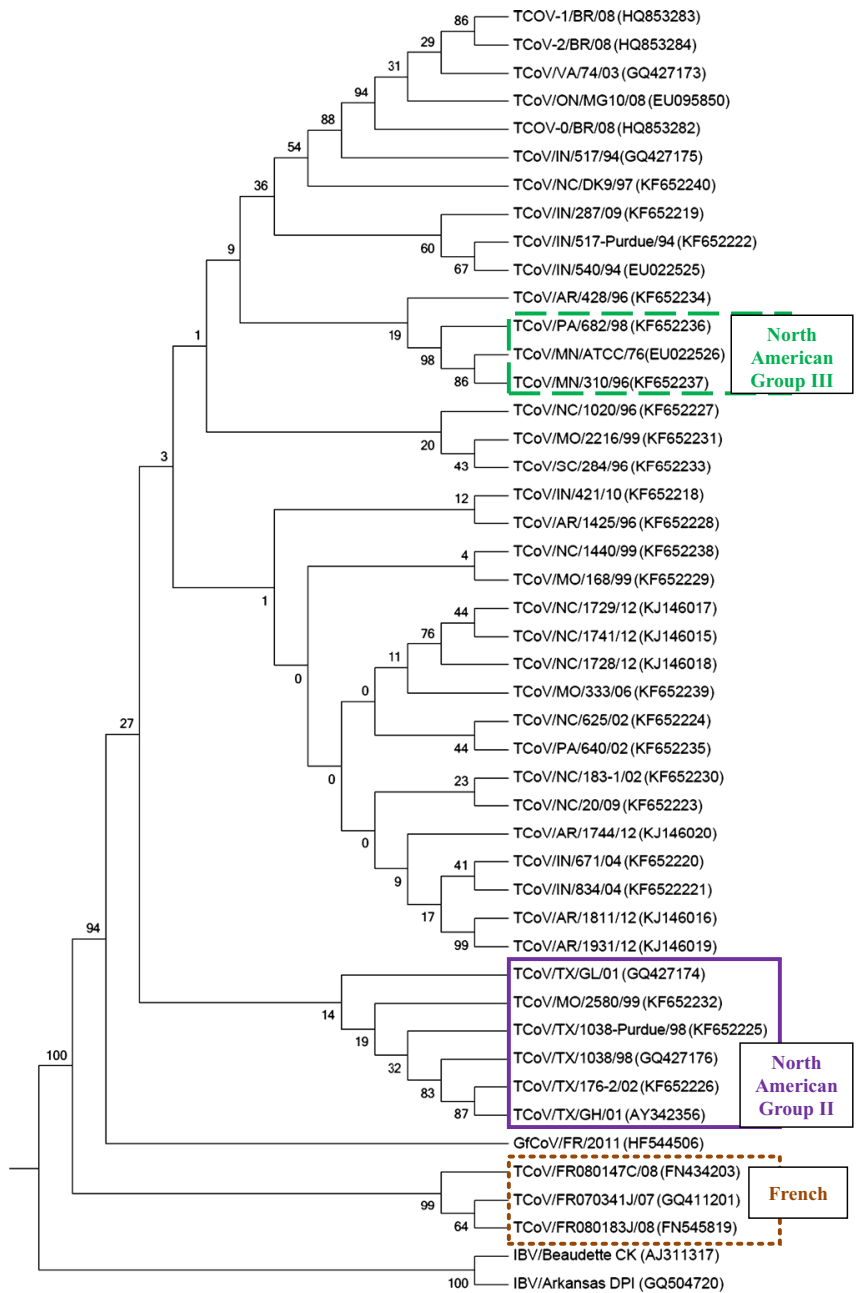

sequence tree was constructed by the maximum-likelihood method and the Kimura 2-parameter model, and the amino acid sequence tree was constructed by the neighbor-joining method and the JonesTaylor-Thonton model in MEGA 6. The bootstrap values were calculated from 1000 trees

TCoV isolates from the outbreaks in Arkansas and North Carolina in 2012 also clustered geographically [6] and could be placed phylogenetically in group $\mathrm{I}$ in the present study. The $99.3 \%$ amino acid sequence identity of the $\mathrm{S}$ proteins of two $\mathrm{TCoV}$ isolates recovered 20 years apart in Minnesota (TCoV/MN/ATCC/76 and TCoV/MN/ 310/96) implied that the TCoV isolate MN/ATCC/76 remained endemic and that no substantial genetic changes occurred over two decades. Conservation of TCoV isolates is also shown in the result that no positive selection of the $\mathrm{S}$ protein was found among the 24 TCoV isolates. Because Indiana isolates from 2004 and 2010 clustered in group I with most North Carolina isolates and Indiana isolates from 1994 and 2009 clustered in group II with Texas isolates, it is most likely that the turkey sources were the same for the turkey 
farms in North Carolina and Indiana in 2004 and 2010, whereas the turkey sources were the same for Texas and Indiana in 1994 and 2009.

In conclusion, the relationship between $\mathrm{TCoV}$ genotypes and the geographic distribution of $\mathrm{TCoV}$ presented in the present study provides crucial information for the monitoring and control of diseases associated with $\mathrm{TCoV}$ infection in the United States.

Acknowledgments The authors thank the US Department of Agriculture for the financial support, and Dr. David Hermes from Perdue Farm (Thorntown, IN, USA) for the turkey eggs and turkey poults used in virus isolation and propagation. The authors also thank Mr. Tom Hooper and Ms. Danna Schrader for their help in virus isolation, and Ms. Jing Dai for her assistance in RT-PCR amplification.

\section{References}

1. Lin TL, Loa CC, Tsai SC, Wu CC, Bryan TA, Thacker HL, Hooper T, Schrader D (2002) Characterization of turkey coronavirus from turkey poults with acute enteritis. Vet Microbiol 84:179-186

2. Cavanagh D, Mawditt K, Sharma M, Drury SE, Ainsworth HL, Britton P, Gough RE (2001) Detection of a coronavirus from turkey poults in Europe genetically related to infectious bronchitis virus of chickens. Avian Pathol 30:355-368

3. Yu MW, Ismail MM, Qureshi MA, Dearth RN, Barnes HJ, Saif YM (2000) Viral agents associated with poult enteritis and mortality syndrome: the role of a small round virus and a turkey coronavirus. Avian Dis 44:297-304

4. Gomaa MH, Yoo D, Ojkic D, Barta JR (2009) Infection with a pathogenic turkey coronavirus isolate negatively affects growth performance and intestinal morphology of young turkey poults in Canada. Avian Pathol 38:279-286

5. Lin TL, Loa CC, Wu CC, Bryan T, Hooper T, Schrader D (2002) Antigenic relationship of turkey coronavirus isolates from different geographic locations in the United States. Avian Dis 46:466-472

6. Day JM, Gonder E, Jennings S, Rives D, Robbins K, Tilley B, Wooming B (2014) Investigating turkey enteric coronavirus circulating in the Southeastern United States and Arkansas during 2012 and 2013. Avian Dis 58:313-317

7. Maurel S, Toquin D, Briand FX, Queguiner M, Allee C, Bertin J, Ravillion L, Retaux C, Turblin V, Morvan H, Eterradossi N (2011) First full-length sequences of the $S$ gene of European isolates reveal further diversity among turkey coronaviruses. Avian Pathol 40:179-189

8. Teixeira MC, Luvizotto MC, Ferrari HF, Mendes AR, da Silva SE, Cardoso TC (2007) Detection of turkey coronavirus in commercial turkey poults in Brazil. Avian Pathol 36:29-33

9. Lin TL, Loa CC, Wu CC (2004) Complete sequences of 3' end coding region for structural protein genes of turkey coronavirus. Virus Res 106:61-70

10. Loa CC, Wu CC, Lin TL (2006) Comparison of 3'-end encoding regions of turkey coronavirus isolates from Indiana, North
Carolina, and Minnesota with chicken infectious bronchitis coronavirus strains. Intervirology 49:230-238

11. Jackwood MW, Boynton TO, Hilt DA, McKinley ET, Kissinger JC, Paterson AH, Robertson J, Lemke C, McCall AW, Williams SM, Jackwood JW, Byrd LA (2009) Emergence of a group 3 coronavirus through recombination. Virology 398:98-108

12. Hughes AL (2011) Recombinational histories of avian infectious bronchitis virus and turkey coronavirus. Arch Virol $156: 1823-1829$

13. Wang CH, Huang YC (2000) Relationship between serotypes and genotypes based on the hypervariable region of the $\mathrm{S} 1$ gene of infectious bronchitis virus. Arch Virol 145:291-300

14. Jia W, Mondal SP, Naqi SA (2002) Genetic and antigenic diversity in avian infectious bronchitis virus isolates of the 1940s. Avian Dis 46:437-441

15. Cao J, Wu CC, Lin TL (2008) Complete nucleotide sequence of polyprotein protein 1 and genome organization of turkey coronavirus. Virus Res 136:43-49

16. Tamura K, Stecher G, Peterson D, Filipski A, Kumar S (2013) MEGA6: molecular evolutionary genetics analysis version 6.0. Mol Biol Evol 30:2725-2729

17. Nei M, Gojobori T (1986) Simple methods for estimating the numbers of synonymous nucleotide substitutions. Mol Biol Evol 3:418-426

18. Yamada Y, Liu XB, Fang SG, Tay FP, Liu DX (2009) Acquisition of cell-cell fusion activity by amino acid substitutions in spike protein determines the infectivity of a coronavirus in cultured cells. PLoS one 4:e6130

19. Chen YN, Wu CC, Lin TL (2011) Identification and characterization of a neutralizing-epitope- containing spike protein fragment in turkey coronavirus. Arch Virol 156:1525-1535

20. Mondal SP, Cardona CJ (2007) Genotypic and phenotypic characterization of the California 99 (Ca199) variant of infectious bronchitis virus. Virus Genes 34:327-341

21. Ndegwa EN, Toro H, van Santen VL (2014) Comparison of vaccine subpopulation selection, viral loads, vaccine virus persistence in trachea and cloaca, and mucosal antibody responses after vaccination with two different Arkansas Delmarva Poultry Industry -derived infectious bronchitis virus vaccines. Avian Dis 58:102-110

22. Lee C-W, Hilt DA, Jackwood MW (2003) Typing of field isolates of infectious bronchitis virus based on the sequence of the hypervariable region in the $\mathrm{S} 1$ gene. $\mathrm{J}$ Vet Diagn Invest 15:344-348

23. Casais R, Thiel V, Siddell SG, Cavanagh D, Britton P (2001) Reverse genetics system for the avian coronavirus infectious bronchitis virus. J Virol 75:12359-12369

24. Phillips JE, Jackwood MW, McKinley ET, Thor SW, Hilt DA, Acevedol ND, Williams SM, Kissinger JC, Paterson AH, Robertson JS, Lemke C (2012) Changes in nonstructural protein 3 are associated with attenuation in avian coronavirus infectious bronchitis virus. Virus Genes 44:63-74

25. Liais E, Croville G, Mariette J, Delverdier M, Lucas MN, Klopp C, Lluch J, Donnadieu C, Guy JS, Corrand L, Ducatez MF, Guerin JL (2014) Novel avian coronavirus and fulminating disease in Guinea fowl, France. Emerg Infect Dis 20:105-108

26. Mihindukulasuriya KA, Wu G, St Leger J, Nordhausen RW, Wang D (2008) Identification of a novel coronavirus from a beluga whale by using a panviral microarray. J Virol 82:5084-5088 